Original Research Paper

\title{
Year-Round Forage Yield Stability through a System Combining Triple-Maize Crops with Winter Barley in Kyushu, Japan
}

\author{
${ }^{1}$ Yingkui Yang, ${ }^{2}$ Yasuyuki Ishii and ${ }^{2}$ Sachiko Idota \\ ${ }^{I}$ Faculty of Agriculture, University of Miyazaki, Japan \\ ${ }^{2}$ Faculty of Agriculture, University of Miyazaki, Miyazaki 889-2192, Japan
}

\author{
Article history \\ Received: 29-11-2015 \\ Revised: $20-12-2015$ \\ Accepted: 20-01-2016 \\ Corresponding Author: \\ Yasuyuki Ishii \\ Faculty of Agriculture, \\ University of Miyazaki, Japan \\ Email: yishii@cc.miyazaki-u.ac.jp
}

\begin{abstract}
Reduction of feeding cost for the beef and dairy cow industry is an urgent matter requiring the intensification of summer and winter forage cropping in Kyushu, Japan. Forage maize is a prominent high-yield summer crop in the region, where it used to be sown from late March to early August. Due to global warming, maize cropping in the common hot summer now easily suffers from heavy rain and typhoons and this contrasts with the need of expanding the growth periods suitable for maize cropping. This study tested the cropping of triple (spring, summer and autumn) maize crops with winter barley to determine its suitability to be cultivated in the region. Winter barley, sown into inter-rows of the previous row crops in mid-November, was harvested from late February to late March, when spring maize was sown earlier than the current season, after the danger of late frost has passed. Summer maize was sown from early June to early July and autumn maize which was sown from late August to mid-September was harvested in mid-to late November. Winter barley yielded 900-1090 g dry matter $(\mathrm{DM}) / \mathrm{m}^{2}$ with $22 \%$ ear DM. Early-planted spring maize which was sown in early March yielded $1600-1880 \mathrm{~g} \mathrm{DM} / \mathrm{m}^{2}$ with $16-28 \%$ ear DM and summer maize yielded $900-1280 \mathrm{~g} \mathrm{DM} / \mathrm{m}^{2}$ with $19-39 \%$ ear DM. However, the autumn maize yield varied from $130-300 \mathrm{~g} \mathrm{DM} / \mathrm{m}^{2}$ without seed maturation to $740-880 \mathrm{~g} \mathrm{DM} / \mathrm{m}^{2}$ with $51-54 \%$ ear DM due to typhoon and cool weather damage. Therefore, triple maize with winter barley cropping can produce a yield of more than $4000 \mathrm{~g} \mathrm{DM} / \mathrm{m}^{2}$, especially from $2600 \mathrm{~g} \mathrm{DM} / \mathrm{m}^{2}$ from winter barley and spring maize crops sown in early March, leading to the conclusion that spring maize sown in early March can be harvested without high risk from weather disasters in the region (290 words $\leq 300$ words, upper-limit).
\end{abstract}

Keywords: Multiple Cropping, Triple-Cropping Maize, Winter Barley, Yield, Ear Dry Matter Percentage

\section{Introduction}

Stable supply of animal feed is essential to develop continuous livestock production. However, in Eastern Asian countries, animal production, which largely depends on imported concentrates, is easily affected by the variable and increasing tendency in imported price of feeds due to adverse climatic conditions in producing areas such as the corn belt in the United States, competition from bio fuel feedstuffs, a variable exchange rate and a fluctuating price of petroleum used in the operation of farm machinery (Msangi et al., 2014). One solution is to strengthen the production of selfsufficiency herbages by increasing yield or by increasing times of cultivation (multi-crop production).

Under global climate change, temperature trends in the major maize production areas from 1980 to 2008 exceeded nearly twice the historical standard deviation (Lobell et al., 2011). Under these circumstances in the United States, the absolute maize yield tended to increase from 1995 to 2012, while greater sensitivity of maize to drought has occurred (Lobell et al., 2014). Current irrigation practice reduces the negative impact of extreme heat shock by $7.2 \%$ on maize yield for an 
additional 10 degree-days above the optimal temperature (Zhang et al., 2015). Selecting an early maturing maize cultivar, combined with planting earlier, is proposed to avoid a mid-summer increase in water loss from evapotranspiration and reduce the need for costly irrigation in the United States (Soderlund et al., 2014). In northern Italy, agro-environmental indicators for dairy farms were analyzed considering both farmers' decision indicators and the resulting pressure indicators on cropping systems, livestock systems and milk production (Gaudino et al., 2014). In northern Italy, cropping management oriented at increasing diversity in cultivars have meant reducing temporal variability in maize yield (Borrelli et al., 2014). In southern Australia, irrigation on dairy farms has been restricted since 2005, consistent with anticipated climate change impacts. Annual-ryegrass grazed pastures, complemented by a double maizeBrassica or ryegrass rotation on $30 \%$ of the farm area, were estimated to lead to an operating surplus, combining with halving irrigated water use (Chapman et al., 2012). In northern China, wheat-maize double cropping has been innovated by intercropping watermelon with maize to get more than a $50 \%$ gross margin, though at higher irrigation and labor input, which should alleviate rural poverty in the region (Huang et al., 2015). In the Philippines, double cropping of rice in the wet season and maize in the dry season was feasible for reducing water use and increasing crop diversification and narrow rows with an intra-plant spacing of $50 \times 20 \mathrm{~cm}$ had the highest biomass and grain yield for maize production among several plant geometries (Chauhan and Opeña, 2013).

In Japan, several research and practical approaches have already been conducted for strengthening domestic forage production by increasing cultivation times for crops. Double-cropping maize production is one of the normal forage cropping systems in Kyushu, southern Japan (Kato, 2011). In the $2000 \mathrm{~s}$, this cropping system would have been suitable to $20.0 \%$ of the Kanto region, located at the center of the Honshu main Islands, where the effective cumulative temperature (ECT, $10^{\circ} \mathrm{C}$ basis) from April to December exceeded $2,300^{\circ} \mathrm{C}$ (Kanno et al., 2014). No-till maize cultivation was introduced by the development of a no-till maize seeder, especially for planting of summer maize in the double-maize cropping system (Kato, 2011). In the next step, five forage crops in a two-year system was investigated to increase the self-sufficiency ratio of animal feed, resulting in a dry matter yield and Total Digestible Nutrient (TDN) yield increase of $22 \%$ compared with the normal cropping system of maize with Italian ryegrass (Kanno et al., 2012). Under the Miyazaki Prefectural Livestock Renovation Plan, triple cropping of forage rice, maize and Italian ryegrass was proposed, though the selection of lands suitable for the triple cropping system is difficult since this system has limited applicability to rotational upland fields with good drainage and the sowing and harvest seasons are also restricted.
Forage crops that can replace a concentrate supply are primarily maize and two-rowed barley in upland fields of the region. Maize is practically sown from late March to early August, while no trials have been carried out for early March sowing of spring maize and late summer sowing from late August to mid-September. To avoid frost damage, spring-sown maize requires cultivation conditions that meet the effective cumulative temperature for that maize cultivar, that avoid the early summer rainy season (Tsuyu) and typhoons and that estimate the risks and benefits of extremely early sowing. The height of maize during growth can be simulated by data on air temperature and solar radiation (Takahashi, 2002). From 20 February to 30 November in Miyazaki, southern Kyushu, the ECT, which is in degreeday units (Bonhomme, 2000), is more than $2800^{\circ} \mathrm{C}$ in a normal year, which can be used to approximate climatic conditions for examination of triple-maize cropping. In Hokkaido, the northern main islands of Japan, it is popular to grow early-maturity maize cultivars (Tamaki et al., 2015) with less than 90 days of Relative Maturity (RM), which have the potential to be cultivated with both earlyspring and autumn sowing in southern Kyushu, if they do not suffer from serious disease.

Two-rowed barley can be grown to emerge and reach an thesis in a cool winter season from mid-November to early March, earlier than wheat (Yoshida and Kamio, 1985) and oats (Kato et al., 2014). The estimated growing days needed to reach the an thesis stage in barley are less than 100 (Mac Master and Wilhelm, 2003) and the cumulative temperature or degree-days in Miyazaki, southern Kyushu, is $800^{\circ} \mathrm{C}$ in a normal year from 20 November to 28 February, which is sufficient for barley to reach an thesis (Yoshida and Kamio, 1985). Direct seeding of barley into the inter-row space of autumn maize before harvest is useful to gain a period for barley to emerge, since the crop needs more than a week for emergence after sowing in a cool climate.

Triple maize and winter barley shared 3 months per crop; spring-and autumn-sown maize crops can have $800^{\circ} \mathrm{C}$ of ECT, summer-sowing maize, $1000^{\circ} \mathrm{C}$ and winter barley, $800^{\circ} \mathrm{C}$ in degree-days. Phenological and yield attributes were compared among two or three cultivars of triple maize crops and a single barley cultivar; thus, a quadruple cropping system with triple (spring-, summer-and autumn-sown) maize crops and winter barley was tested for its potential application to the southern Kyushu region.

\section{Materials and Methods}

The experiment was a 2-year study conducted in an experimental field of the Faculty of Agriculture, University of Miyazaki, Miyazaki, Japan $\left(31^{\circ} 49^{\prime} 40^{\prime \prime} \mathrm{N}\right.$, $131^{\circ} 24^{\prime} 46^{\prime \prime}$ E, $28 \mathrm{~m}$ a.s.l., soil type a fine volcanic ash soil andosol), initiated in November 2013 and ending in 
November 2015. The potential of a multiple-cropping system of triple (spring-, summer- and autumn-sown) maize crops and winter barley in the region was tested. The experimental design was a split plot with sowing dates being the main-plot and cultivar the split-plot factors with four replications, except for winter tworowed barley, which was a single cultivar, Wasedorinijou (early-maturing variety, Yukijirushi, Co. Ltd., Sapporo, Japan, abbreviated W), sown uniformly at $70 \mathrm{~kg} \mathrm{ha}^{-1}$ on 13 November 2013 and on 13 November 2014. Plot size was $3 \times 3.5 \mathrm{~m}\left(10.5 \mathrm{~m}^{2}\right)$ with $50 \mathrm{~cm}$ row spacing. Before planting of every crop, the soil was tilled using a cultivator to a depth of around $20 \mathrm{~cm}$ followed by flattening by hand, except for inter-row direct seeding of winter barley with no tillage in November 2014. Fermented manure supplied at $30 \mathrm{Mg}$ Fresh Weight $(\mathrm{FW}) /$ ha containing $1.3 \% \mathrm{~N}$ and slaked lime at $1.5 \mathrm{Mg}$ $\mathrm{ha}^{-1}$ were broadcast prior to planting.

The maize cultivars examined for spring and autumn sowing, released for cultivation in Hokkaido, were extremely early-maturing LG3215 (Relative Maturity (RM) 75, Snow Brand, Yukijirushi, Co. Ltd., Sapporo, Japan, abbreviated L) and Solide (RM 78, Snow Brand, abbreviated S) and early-maturing Anjou 284 (RM 90, Snow Brand, abbreviated A) in 2014 and Solide and Anjou 284 in 2015, due to the lowest yield coming from LG3215 in 2014. The cultivars for summer sowing, also released for production in Hokkaido, were earlymaturing KD510 (RM 100, Kaneko Seeds Co. Ltd., Maebashi, Japan, abbreviated KD) and NS105 Super (RM 105, Kaneko Seeds, abbreviated NS) both in 2014 and 2015. The shift from winter barley to spring-sown maize was conducted in two growing stages of winter barley, at the milk-ripe stage, harvested on 10 March, 2014 and the dough-ripe stage, on 26 March. Springsown maize was seeded at two seeds per spot at a spacing of $15 \times 50 \mathrm{~cm}$ after the barley harvest on 17 March, as an early-sown plot and on 29 March, as a normally sown plot. In 2015, spring-sown maize was seeded on 3 March, as an extremely early-sown plot and on 17 March, as an early-sown plot. Plant spacing for summer-sown maize was fixed at $20 \times 50 \mathrm{~cm}$. Maize plants were thinned to one plant per spot at the 3 rd to 5 th leaf stage for each crop. The shifts from spring- to summer-sown maize and from summer-to autumn-sown maize were conducted when maize reached the doughripe or milk-ripe stage, except for autumn-sown maize, which was harvested uniformly on 21 November 2014 and on 16 November 2015.

Compound fertilizers, containing $\mathrm{N}, \mathrm{P}_{2} \mathrm{O}_{5}$ and $\mathrm{K}_{2} \mathrm{O}$ at $14 \%$ each, were broadcast at the tillering, maximum tiller number and booting stages at $40 \mathrm{~kg}$ of each element/ha/application for winter barley and were broadcast at the 3 rd to 5 th leaf stage, 7 to 9 th leaf stage and heading or silking stage at $50 \mathrm{~kg}$ of each element/ha/application for maize. Phenological attributes of plant height, tiller number and fresh weight were determined for two individual quad rats of $0.25 \mathrm{~m}^{2}$ for barley and on a per plant basis for two maize plants for each replication of both the time of fertilization and plant harvest. After measuring fresh weight, plants were divided into Leaf Blade (LB), stem inclusive of Leaf Sheath (ST) and withering fraction (W) for barley and maize, in addition to Tassel (T) and ear (E) for maize and were dried by a ventilation oven at $70^{\circ} \mathrm{C}$ for $72 \mathrm{~h}$ to determine the percentage of Dry Matter (DM).

One-way analysis of variance was carried out using Excel Statistics 2010 software (Social Information Service, Tokyo, Japan). Differences in means were evaluated using Fisher's least significant difference test at the $5 \%$ level.

\section{Results}

\section{Growth and Yielding Ability of Winter Barley}

In the first wintering season from 2013-2014, plant height increased over time to reach a plateau of more than $120 \mathrm{~cm}$ on 10 March, 2014 at the milk-ripe stage harvest (Fig. 1). Tiller density increased linearly with time and reached a plateau at $700-800 / \mathrm{m}^{2}$ in midJanuary, at the maximum tiller stage. A slight increase in tiller density after heading was derived from lateemerging tillers due to stem elongation of mother tillers, which resulted in an increase in light intensity at the base of the canopy (Fig. 2). DM yield increased almost exponentially with time and reached $930 \mathrm{~g} / \mathrm{m}^{2}$ at the milkripe stage and $1090 \mathrm{~g} / \mathrm{m}^{2}$ at the dough-ripe stage (Fig. 3).

In the second season from 2014-2015, plant height reached over $100 \mathrm{~cm}$ at heading and $120 \mathrm{~cm}$ at the fullheading stage (Fig. 1). Tiller density increased almost linearly with time and reached the maximum tiller stage at $1240 / \mathrm{m}^{2}$ in the end of January and then decreased to a stable density of $930 / \mathrm{m}^{2}$ at heading and $910 / \mathrm{m}^{2}$ at the full-heading stage (Fig. 2). The final DM yield reached $900 \mathrm{~g} / \mathrm{m}^{2}$ at the heading stage for the extremely early plot and $1010 \mathrm{~g} / \mathrm{m}^{2}$ at the full-heading stage for the early-sown plot (Fig. 3).

\section{Growth and Yielding Ability of Triple Maize Crops}

In the 2014 growing season, growth and yielding ability in triple maize crops were compared in two plots for each sowing season.

In the early-sown spring maize, plant height tended to be highest in Solide at the milk-ripe stage, followed by Anjou 284 and LG3215, while at the dough-ripe stage, plant height did not differ significantly among cultivars (Fig. 4A). DM yield was the highest in Anjou 284 at $1800 \mathrm{~g} / \mathrm{m}^{2}$, followed by Solide at 1520 $\mathrm{g} / \mathrm{m}^{2}$ and LG3215 at $1490 \mathrm{~g} / \mathrm{m}^{2}$, showing a consistent ear percentage of $16-17 \%$ among cultivars (Fig. 5). 


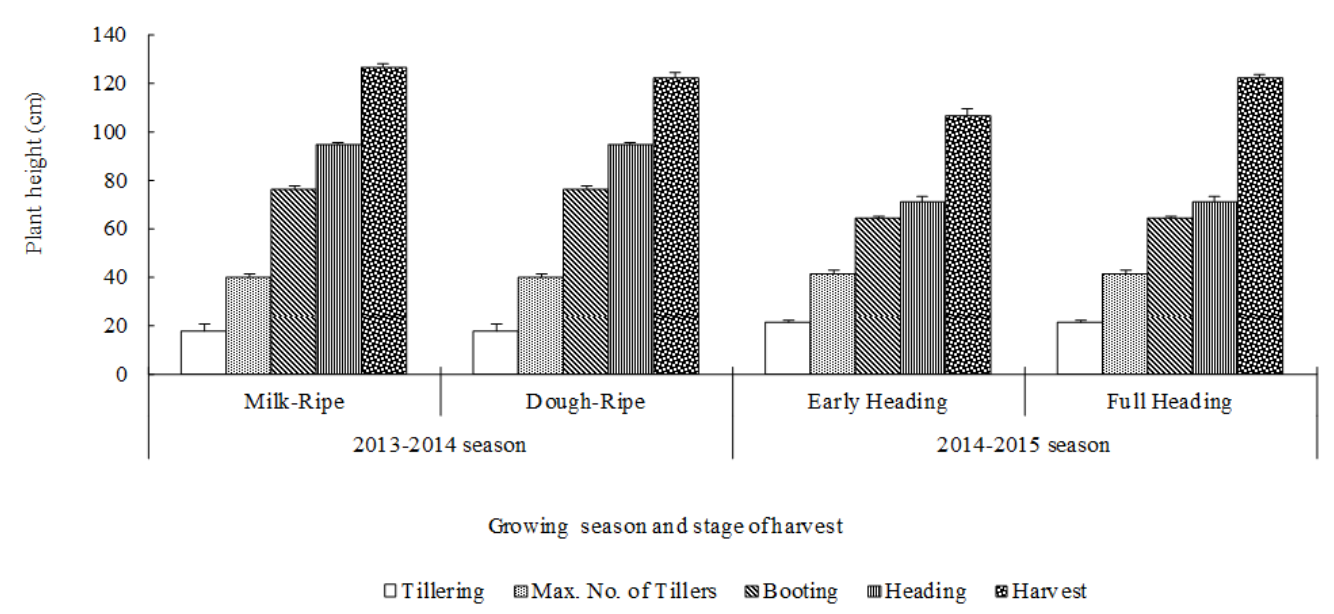

Fig. 1. Changes in plant height of winter barley in two cropping seasons, expressed as mean \pm standard deviation

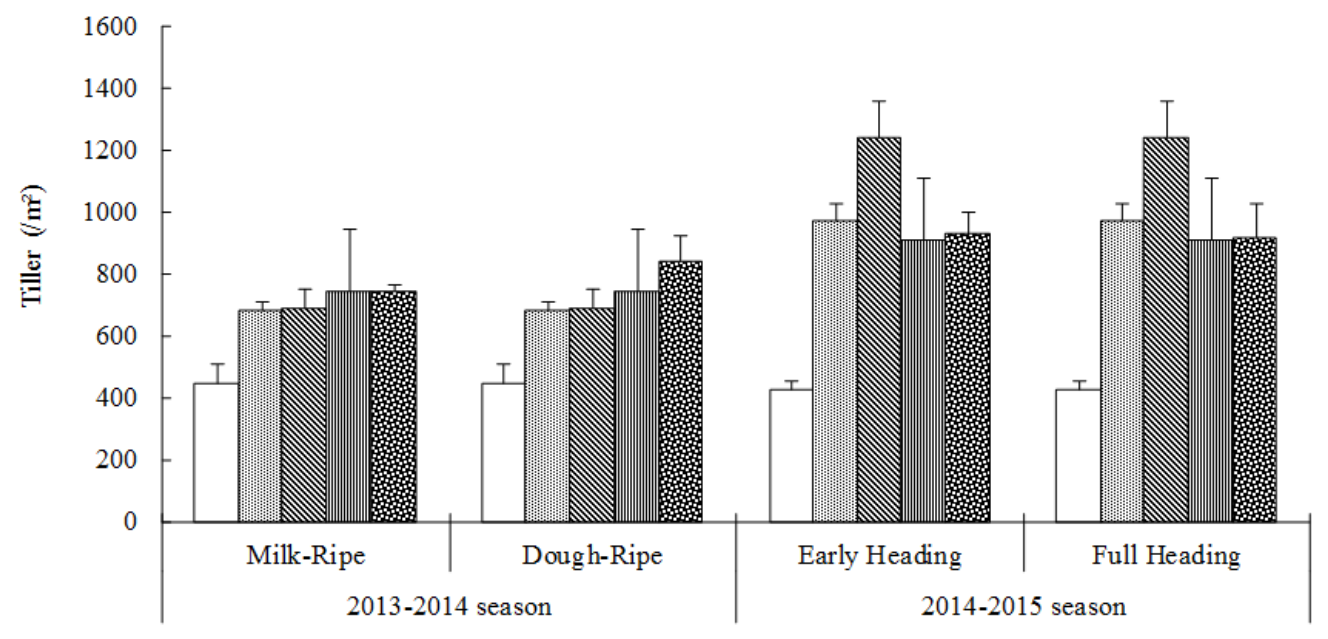

Growing season and stage of harvest
$\square$ Tillering
国Max. No. of Tillers
$\mathbb{\$}$ Booting
m. Heading
Harvest

Fig. 2. Changes in tiller density of winter barley in two cropping seasons, expressed as mean \pm standard deviation

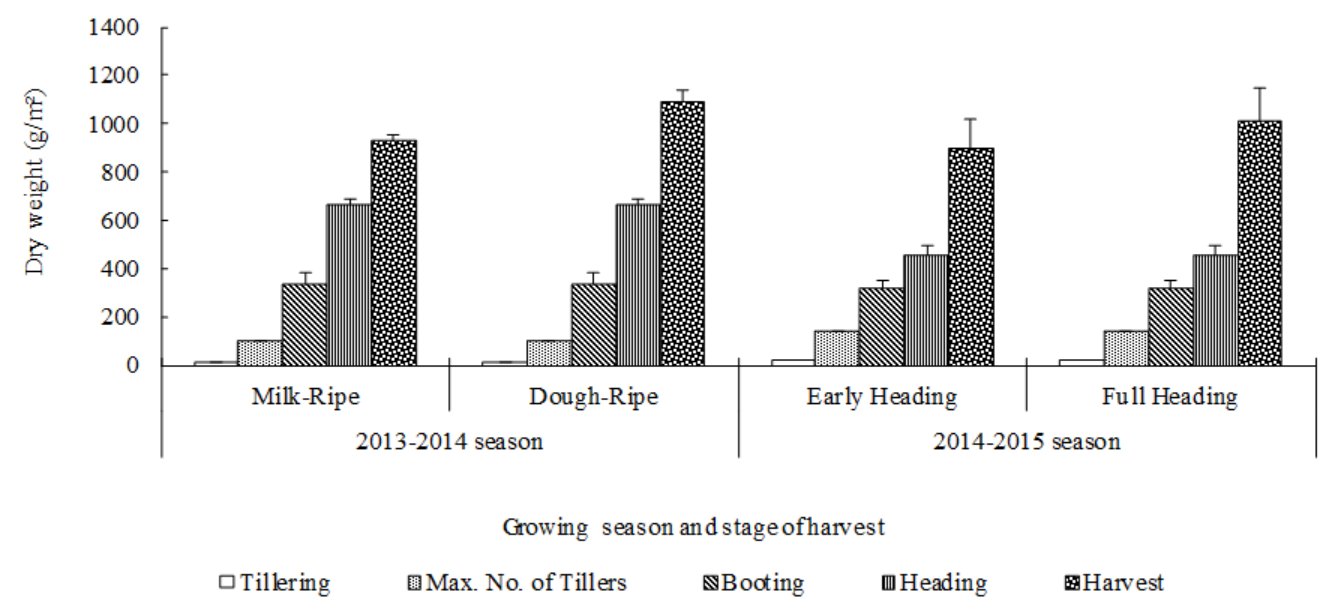

Fig. 3. Changes in dry weight of winter Barley in two cropping seasons, expressed as mean \pm standard deviation 


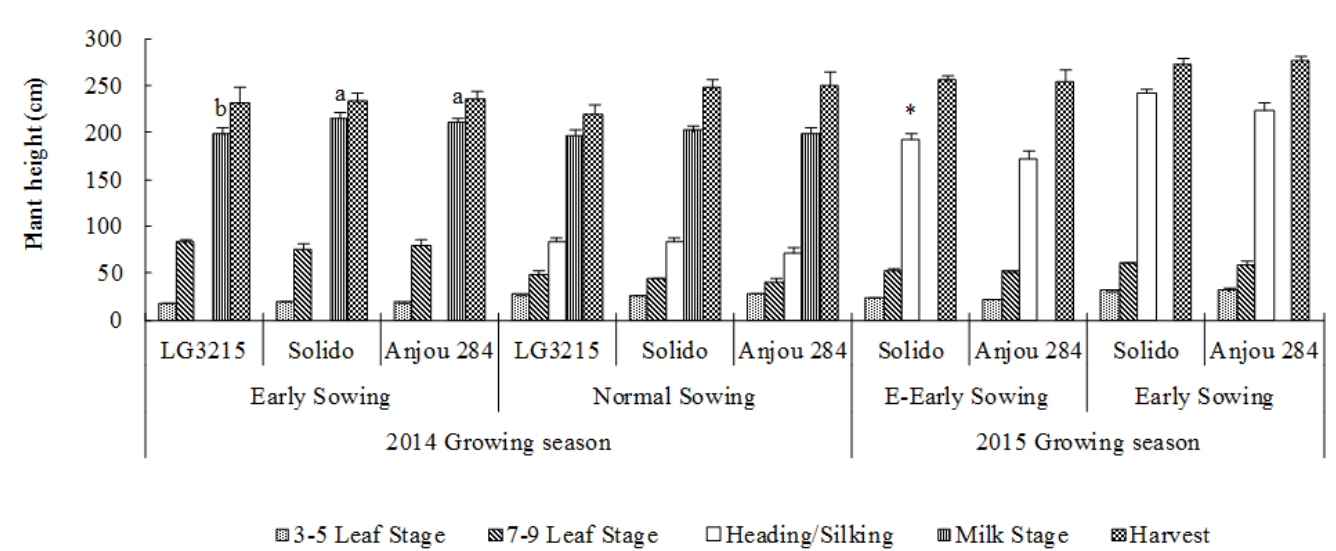

(A)

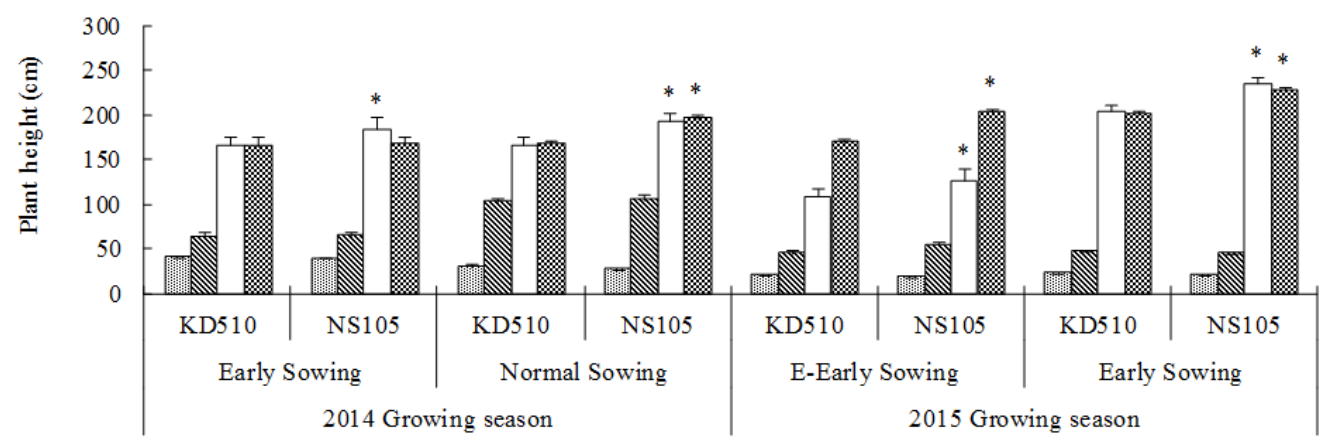

3-5 Leaf Stage $\quad$ 7-9 Leaf Stage $\quad$ Heading/Silking $\otimes$ Harvest

(B)

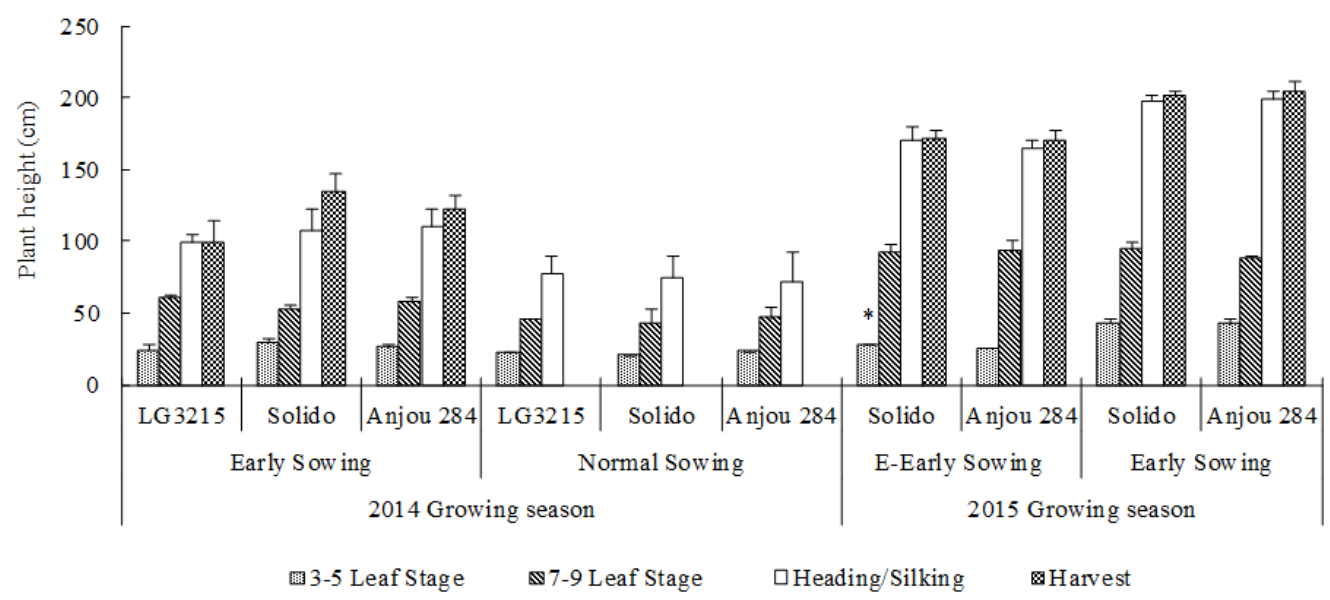

(C)

Fig. 4. Changes in plant height in (A) spring-sown maize (B) summer-sown maize (C) autumn-sown maize in two cropping seasons, expressed as mean \pm standard deviation. E-Early, extremely early, a-b: $p<0.05$, *: $p<0.05$ among cultivars with the same sowing time and at the growth stage

In the normal-sown spring maize, plant height did not differ significantly among cultivars, except for the dough-ripe stage, when it was lowest in LG3215 (Fig. 4A). DM yield tended to be lower in normal-sown than early-sown maize, due to a typhoon in late June before harvest of the normal-sown plot, while a higher ear percentage of $29-30 \%$ was obtained in normal-sown plots. The ranking in DM yield among cultivars at the dough-ripe stage was similar for the early-and normalsown plots (Fig. 5). 


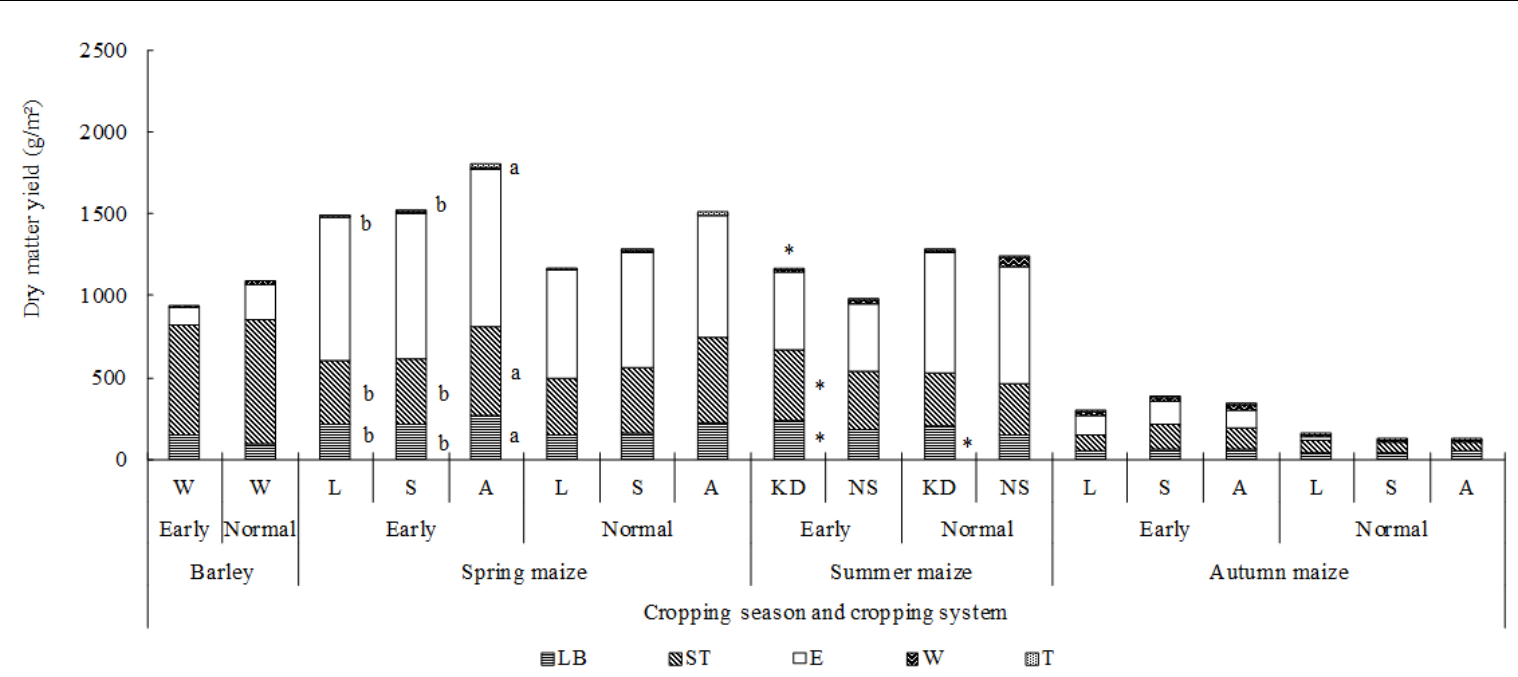

Fig. 5. Changes in dry matter yield of plant fractions in barley and spring-, summer-, autumn-sown maize in 2013-2014 cropping season. Cultivar: W (Wasedori Ni Jou), L (LG3215), S (Solido), A (Anjou284), KD (KD510), NS (NS105Super). Plant fraction: LB (leaf blade), ST (stem inclusive of sheath), E (ear), W (withering), T (tassel), a-b: p<0.05, *: p $<0.05$ among cultivars in the same cropping season and cropping system

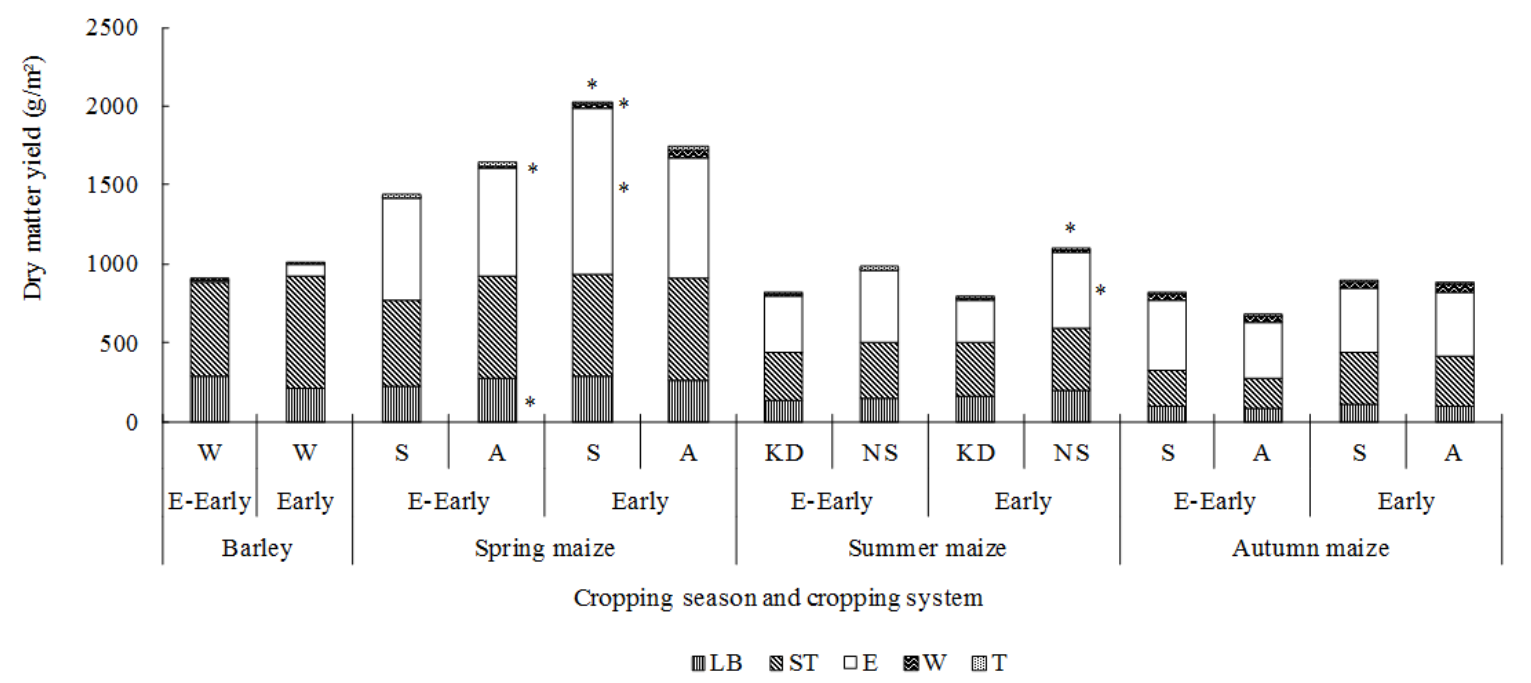

Fig. 6. Changes in dry matter yield of plant fractions in barley and spring-, summer- and autumn-sown maize in 2014-2015 cropping season. E-Early, extremely early. Cultivar: W (Wasedori Ni Jou), L (LG3215), S (Solido), A (Anjou284), KD (KD510), NS (NS105Super). Plant fraction: LB (leaf blade), ST (stem inclusive of sheath), E (ear), W (withering), T (tassel)

In early-sown summer maize, plant height increased rapidly after thinning to reach a maximum at the silking stage, when NS105Super was significantly higher than KD510 (Fig. 4B). DM yield at the milk-ripe stage was higher in KD510 at $1170 \mathrm{~g} / \mathrm{m}^{2}$ than NS105Super at 980 $\mathrm{g} / \mathrm{m}^{2}$, with the ear percentage reaching $22-23 \%$ (Fig. 5). In normal-sown summer maize, plant height was significantly higher in NS105Super than KD510 at both the silking and milk-ripe stages (Fig. 4B), while DM yield tended to be higher in KD510 at $1290 \mathrm{~g} / \mathrm{m}^{2}$ than in NS105Superat $1240 \mathrm{~g} / \mathrm{m}^{2}$, which was lower than for both sowing dates of spring maize (Fig. 5).

In early-sown autumn maize, plant height at the heading stage reached a range of 100 to $110 \mathrm{~cm}$. Height at the blister-ripe stage was highest in Solide at $145 \mathrm{~cm}$, followed by Anjou 284 and LG3215 (Fig. 4C), which corresponded with the highest observed DM yield of 380 $\mathrm{g} / \mathrm{m}^{2}$ (Fig. 5). In normal-sown autumn maize, plant height at the heading stage was as low as around $80 \mathrm{~cm}$ for all three cultivars (Fig. 4C) and DM yield at the headingsilking stage was also a slow as $150 \mathrm{~g} / \mathrm{m}^{2}$ in LG3215, followed by Solido and Anjou284 at $120 \mathrm{~g} / \mathrm{m}^{2}$ (Fig. 5). 

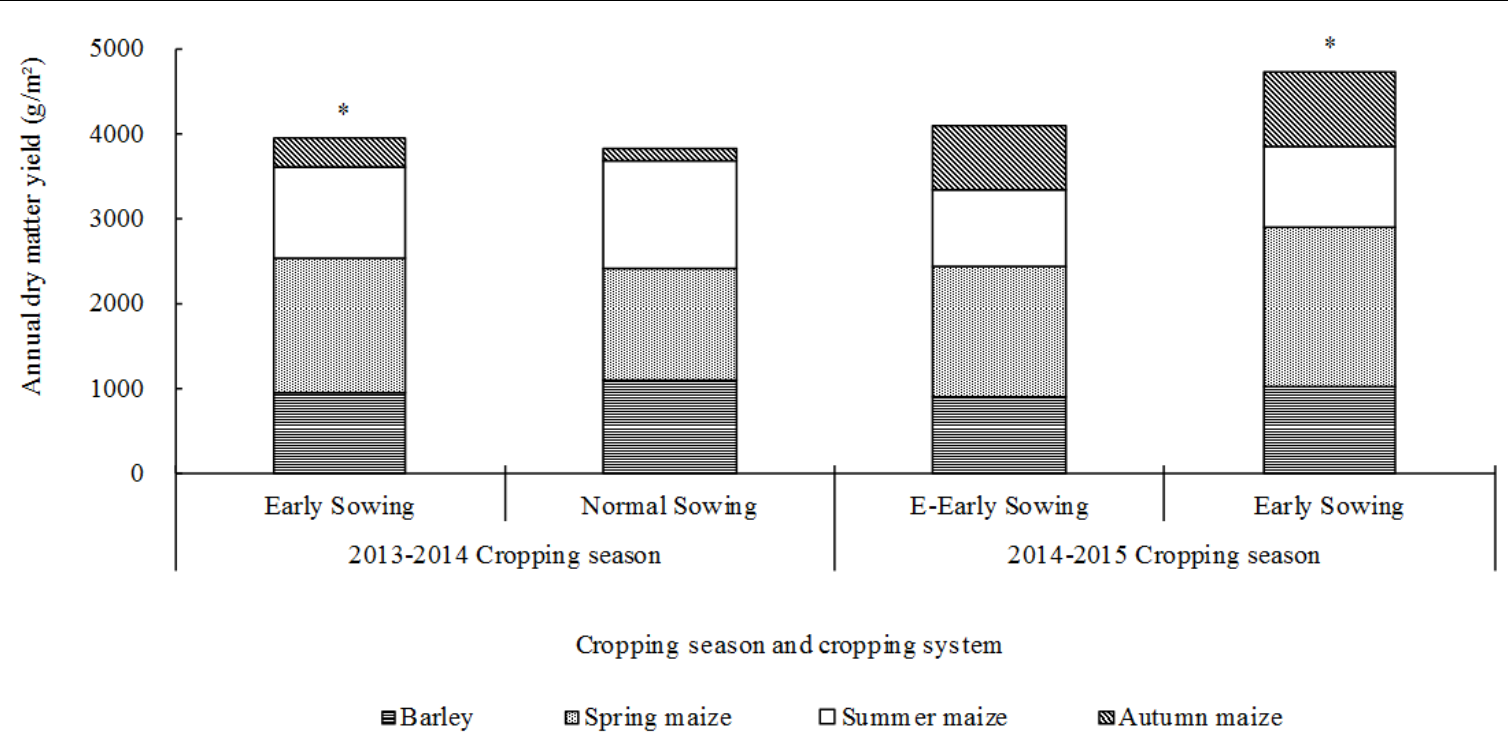

Fig. 7. Cumulative dry matter yield per yearly cropping season in 2013-2014 and 2014-2015. Spring-, summer- and autumn-maize yields were averaged across all cultivars examined in each crop. E-Early, extremely early. *: $p<0.05$

Also in the 2015 growing season, growth and yielding ability in triple maize crops were compared between two plots in each sowing season.

In the extremely early-sown spring maize, plant height at the silking stage was significantly higher in Solido than Anjou 284, while no difference between them appeared at the dough-ripe stage (Fig. 4A). DM yield at harvest was higher in Anjou 284 at $1640 \mathrm{~g} / \mathrm{m}^{2}$ than in Solide at $1440 \mathrm{~g} / \mathrm{m}^{2}$, showing ear percentages of 18 and $22 \%$, respectively (Fig. 6). In early-sown spring maize, plant height reached over $250 \mathrm{~cm}$ in both cultivars at harvest (Fig. 4A). DM yield was higher in Solido at $2020 \mathrm{~g} / \mathrm{m}^{2}$ than Anjou 284 at $1740 \mathrm{~g} / \mathrm{m}^{2}$ when harvested at the dough-ripe stage (Fig. 6).

In the extremely early-sown plot, plant height of summer maize at the silking stage was significantly higher in NS105Super than KD510, which also occurred in the early-sown plot, when summer maize was harvested at the milk-ripe stage (Fig. 4B). DM yield at harvest tended to be higher in NS105 Super at $980 \mathrm{~g} / \mathrm{m}^{2}$ than KD510 at $820 \mathrm{~g} / \mathrm{m}^{2}$, the same genotypic differences observed in the early-sown plot, where NS105 Super had significantly higher yield at $1100 \mathrm{~g} / \mathrm{m}^{2}$ than KD510 at $800 \mathrm{~g} / \mathrm{m}^{2}$, showing ear percentages of 22 and $16 \%$, respectively (Fig. 6).

In the extremely early-sown plot, plant height of autumn maize at the silking stage tended to be higher in Solido than Anjou 284, while no genotypic difference between the two cultivars appeared at the milk-dough ripe stage (Fig. 4C). DM yield at harvest tended to be higher in Solide at $810 \mathrm{~g} / \mathrm{m}^{2}$ than in Anjou 284 at 670 $\mathrm{g} / \mathrm{m}^{2}$, showing a similar ear percentage of $52-56 \%$ (Fig. $6)$. In the early-sown plot, plant height of autumn maize reached around $200 \mathrm{~cm}$ in both cultivars at harvest (Fig.
4C). DM yield was similar between Solide at $890 \mathrm{~g} / \mathrm{m}^{2}$ and Anjou 284 at $870 \mathrm{~g} / \mathrm{m}^{2}$, showing a similar ear percentage of $45-47 \%$ when harvested at the blister-milk ripe stage (Fig. 6).

Based on these growth and yield data, annual DM yield in winter barley with triple maize crops averaged across the examined cultivars reached around $4000 \mathrm{~g} / \mathrm{m}^{2}$ in the 2013-2014 season and even higher in the 20142015 growing season. In addition, winter barley with early-sown spring maize showed a yielding ability of $2500-2800 \mathrm{~g} / \mathrm{m}^{2}$ in both growing seasons (Fig. 7), which was minimally influenced by variable climatic conditions such as heavy precipitation and typhoons.

\section{Discussion}

In this study, quadruple cropping was examined for suitability in southern Kyushu, Japan. In this cropping system, cultivation of each crop must be complete in three months to avoid overlapping the cultivation period. Frosty winter periods of three months from December to February can be used for the cultivation of winter barley. With triple maize crops, a three-month period is allotted to each crop; spring-sown maize from March to May, summer-sown maize from June to August and autumnsown maize from September to November. In addition, barley needs more than a week for emergence after sowing in a cool climate (Tamaki et al., 2002) and thus barley was sown in inter-row spaces of autumn-sown maize before its harvest in 2014 .

In spring-and autumn-sown maize, the lower temperature regimes, which have only $800^{\circ} \mathrm{C}$ of ECT in a three-month period, require extremely early-maturing maize cultivars released for cultivation in Hokkaido. 
These cultivars have less than 80 days of RM, in contrast with the early-maturing cultivar having an RM of 90 days. Even for the growth of summer-sown maize, an early-maturing cultivar with an RM of 100-105 days should be a good fit to the three-month hot summer season, since the mean air temperature in the period from June through August would be higher than $20^{\circ} \mathrm{C}$, which means more than $10^{\circ} \mathrm{C}$ of effective temperature accumulated per day. The maize cultivars selected for spring-and autumn-sowing were judged by the length of their RM to fit the three-month growing period. Therefore, these cultivars don't have enough lodging resistance to typhoons or pest resistance, such as to southern rust, southern leaf blight and wallaby ear disease, which happen quite often in the region when maize is sown in the summer (NARO, 2001).

Intensification of normal double-cropping of a summer crop such as maize or sorghum with a winter crop, i.e., Italian ryegrass or oats (Idota and Ishii, 2007; 2014; Aydin et al., 2010) to the present quadruplecropping of triple maize crops and a winter barley crop requires high labor input for tillage, additional fertilizer supply and harvesting of the additional two crops cultivated per year. However, as global climate change progresses (Lobell et al., 2011; 2014), the needed increase in self-sufficient herbage production was achievable by this novel triple maize with winter barley quadruple-cropping system, resulting in more than 40 $\mathrm{Mg} \mathrm{ha}^{-1}$ of DM yield, similar to the yield record for a perennial tropical grass, Napier grass (Ishii et al., 2005). In Japan, some maize crops are harvested by contractors using large corn harvesters or roll balers (Shito et al., 2011), which require roughly equivalent labor effort between seasons. Therefore, intensification of maize cropping into multiple crops builds employment opportunities for contract workers.

Yield stability (Borrelli et al., 2014) in winter barley was quite constant, as shown in Fig. 3, being consistent with research in the UK (McMaster and Wilhelm, 2003). However, typhoons adversely affected maize yield for the summer-sowing in 2014 and early growth of the autumn-maize sown in early and mid-September in 2014 , leading to failure of grain filling and low yield in a range of 130-300 $\mathrm{g} \mathrm{DM} / \mathrm{m}^{2}$ (Fig. 5), which was almost corresponded with the yield of autumn-sown Italian ryegrass harvested in December. Contrarily, when the sowing of autumn-maize was completed in late August, the yielding level increased to $740-880 \mathrm{~g} \mathrm{DM} / \mathrm{m}^{2}$ with $51-54 \%$ ear DM in 2015. Therefore, autumn-maize should be sown until the end of August to escape from low yield due to cooler grain filling period. The long Tsuyu rainy season in June to July 2015 reduced the summer-sown maize yields severely due to retardation of growth after much of the crop was submerged following heavy precipitation (Ignacio et al., 2014). Therefore, triple maize cropping offers the possibility of avoiding climatic disasters (Idota and Ishii, 2007) on each crop in the maize growing season.

Maize and barley can be cultivated for multipurpose use, such as phytoremediation (Liu et al., 2015) and pest and weed control (Komatsuzaki et al., 2001; El-Metwally et al., 2010; Poppy et al., 2012; Haque et al., 2013; Odhiambo et al., 2015) in addition to solely for forage use.

The benefits of sowing spring maize in early March were not expected, though yield stability (Borrelli et al., 2014) in the extremely early-sown spring maize should be addressed soon.

\section{Conclusion}

Annual DM yield in the winter barley with triple maize cropping system reached a yield of 3900-4400 $\mathrm{g} / \mathrm{m}^{2}$ (39-44 $\mathrm{Mg} \mathrm{ha}^{-1}$ ) in both the first and second growing seasons and winter barley with the early-sown spring maize showed a yield of around $2500-2800 \mathrm{~g} / \mathrm{m}^{2}$ (25-28 $\left.\mathrm{Mg} \mathrm{ha}^{-1}\right)$, which appeared to be hardly influenced by adverse climatic conditions such as heavy precipitation. Even though intensifying the cultivation of crops requires additional labor and shifting from a previous to a next crop requires favorable field conditions for the operation of field machinery, quadruple cropping offers several benefits to increase the annual yield of field crops and to avoid the disastrous loss of yield caused by the increasing frequency of typhoons due to climate change.

\section{Funding Information}

These experiments were partly supported by funding from the Interdisciplinary Graduate School of Agriculture and Engineering, University of Miyazaki.

\section{Author's Contributions}

We certify that all persons listed as authors have made substantial contributions to the work reported in this manuscript.

Yingkui Yang and Yasuyuki Ishii: Both conducted field research, prepared the literature review, analyzed and interpreted the results and drew conclusions.

Sachiko Idota: Analyzed and interpreted the results and made comments on the discussion.

\section{Ethics}

The manuscript represents original and valid work and does not infringe or violate any copyright agreements or any other personal or proprietary rights and neither this manuscript nor one with substantially similar content has been published or is being considered for publication elsewhere. 


\section{References}

Aydin, N., Z. Mut, H. Mut and I. Ayan, 2010. Effect of autumn and spring sowing dates on hay yield and quality of oat (Avena sativa L.) genotypes. J. Anim. Vet. Adv., 9: 1539-1545. DOI: $10.3923 /$ javaa.2010.1539.1545

Bonhomme, R., 2000. Bases and limits to using 'degree.day' units. Eur. J. Agronomy, 13: 1-10. DOI: 10.1016/S1161-0301(00)00058-7

Borrelli, L., F. Castelli, E. Ceotto, G. Cabassi and C. Tomasoni, 2014. Maize grain and silage yield and yield stability in a long-term cropping system experiment in Northern Italy. Eur. J. Agronomy, 55: 12-19. DOI: 10.1016/j.eja.2013.12.006

Chapman, D.F., K. Dassanayake, J.O. Hill, B.R. Cullen and N. Lane, 2012. Forage-based dairying in a waterlimited future: Use of models to investigate farming system adaptation in southern Aus. J. Dairy Sci., 95: 4153-4175. DOI: $10.3168 /$ jds.2011-5110

Chauhan, B.S. and J. Opeña, 2013. Effect of plant geometry on growth and yield of corn in the rice-corn cropping system. Am. J. Plant Sci., 4: 1928-1931. DOI: 10.4236/ajps.2013.410237

El-Metwally, I.M., M.S. Abd El-Salam and R.M.H. Tagour, 2010. Nitrogen fertilizer levels and some weed control treatments effects on barley and associated weeds. Agric. Biol. J. N. Am., 1: 992-1000.

DOI: 10.5251/abjna.2010.1.5.992.1000

Gaudino, S., I. Goia, C. Grignani, S. Monaco and D. Sacco, 2014. Assessing agro-environmental performance of dairy farms in northwest Italy based on aggregated results from indicators. J. Environ. Manage., 140: 120-134.

DOI: 10.1016/j.jenvman.2014.03.010

Haque, M.M., M.S. Islam, M.S. Jahan and M.M. Islam, 2013. Yield response of barley varieties under two different tillage conditions in moderately saline soils of Khulna. Res. Desk, 2: 270-274.

Huang, C., Q. Liu, N. Heerink, T. Stomph and B. Li et al., 2015. Economic performance and sustainability of a novel intercropping system on the North China plain. PLoS One, 10: e0135518- e0135518.

DOI: 10.1371/journal.pone.0135518

Idota, S. and Y. Ishii, 2007. Annual variation in herbage dry matter yield under some forage cropping systems on the heavy soil in southern Kyushu. Jap. J. Grassland Sci., 53: 93-101.

Idota, S. and Y. Ishii, 2014. Effect of dehydrated digested effluent of manure on yield and quality of annual forages and soil chemical properties in Southern Kyushu. Agric. Sci., 5: 843-849. DOI: $10.4236 /$ as.2014.510090

Ignacio, C., K. Roozeboom and D. Jardine, 2014. Effect of water-logged soils on corn growth and yield. Kansas State University.
Ishii, Y., N. Yamaguchi and S. Idota, 2005. Dry matter production and in vitro dry matter digestibility of tillers among napiergrass (Pennisetum purpureumSchumach) varieties. Grassl. Sci., 51: 153-163. DOI: 10.1111/j.1744-697X.2005.00021.X

Kanno, T., S. Morita, S. Sato, S. Kurokawa and H. Sazarashi et al., 2012. Determination of the effective cumulative temperature required for second cropping of corn (Zea mays L.) at the northern boundary for the double-cropping system. Proceedings of the 4th Japan-China-Korea Joint Symposium on Grassland Agriculture and Livestock Production, (ALP' 12), pp: 64-65.

Kanno, T., S. Morita, H. Sasaki and K. Nishimura, 2014. Recent situation and future prediction for areas suitable for double cropping of corn (Zea mays L.) production in Japan's Kanto Region. Japanese J. Grassl. Sci., 60: 161-166. DOI: 10.14941/grass.60.161

Kato, N., 2011. Corn no-till cultivation in Kyushu Region of Japan. J. Japanese Society Grassland Sci., 57: 172-175.

Kato, N., I. Hattori, Y. Kiyomura, M. Katsura and R. Kobayashi, 2014. Waterlogging tolerance in different growth stages among barley, Italian ryegrass and oat. J. Warm Region. Soc. Anim. Sci., Jap., 57: 97-104. DOI: 10.11461/jwaras.57.97

Komatsuzaki, M., S. Moriizumi and O. Endo, 2001. Subterranean clover management to enhance reseeding in silage corn production. Jap. J. Farm Work Res., 36: 3-8. DOI: 10.4035/jsfwr.36.3

Liu, Y., K. Liu, Y. Li, W. Yang and F. Wu et al., 2015. Cadmium contamination of soil and crops is affected by intercropping and rotation systems in the lower reaches of the Minjiang River in southwestern China. Environ. Geochem. Health. DOI: $10.1007 / \mathrm{s} 10653-015-9762-4$

Lobell, D.B., W. Schlenker and J. Costa-Roberts, 2011. Climate trends and global crop production since 1980. Science, 333: 616-620. DOI: $10.1126 /$ science. 1204531

Lobell, D.B., M.J. Roberts, W. Schlenker, N. Braun and B.B. Little et al., 2014. Greater sensitivity to drought accompanies maize yield increase in the U.S. Midwest. Science, 344: 516-519. DOI: $10.1126 /$ science. 1251423

McMaster, G.S. and W.W. Wilhelm, 2003. Phenological responses of wheat and barley to water and temperature: Improving simulation models. J. Agric. Sci., 141: 129-147. DOI: $10.1017 / \mathrm{S} 0021859603003460$

Msangi, S., D. Enahoro, M. Herrero, N. Magnan and P. Havlik et al., 2014. Integrating livestock feeds and production systems into agricultural multi-market models: The example of IMPACT. Food Policy, 49: 365-377. DOI: 10.1016/j.foodpol.2014.10.002 
NARO, 2001. Illustrated encyclopedia of forage crop diseases. National Agriculture and Food Research Organization.

Odhiambo, J.A., U. Norton, D. Ashilenje, E.C. Omondi and J.B. Norton, 2015. Weed dynamics during transition to conservation agriculture in western Kenya maize production. PLoS One, 10: e0133976e0133976. DOI: 10.1371/journal.pone.0133976

Poppy, G.M., P.C. Jepson, J.A. Pickett and M.A. Birkett, 2012. Achieving food security for one million subSaharan African poor through push-pull innovation by 2020. Phil. Trans. R. Soc. B, 369: 2012028420120284. DOI: $10.1098 /$ rstb.2012.0284

Shito, H., Y. Tachibana, T. Kawaide, H. Okajima and T. Kitanaka et al., 2011. Improvement of suitability for farm work and calculation of minimum harvesting area for introducing a self-propelled harvesting roll baler. Japanese J. Grassl. Sci., 57: 13-20.

Soderlund, S., F.N. Owens and C. Fagan, 2014. Forages and pastures symposium: Development of and field experience with drought-tolerant maize. J. Anim. Sci., 92: 2823-2831. DOI: 10.2527/jas2013-7373

Takahashi, S., 2002. A model predicting forage maize growth based on temperature and solar radiation. Jpn. J. Grassl. Sci., 48: 43-49.
Tamaki, M., S. Kondo, T. Itani and Y. Goto, 2002. Temperature responses of leaf emergence and leaf growth in barley. J. Agric. Sci., 138: 17-20. DOI: $10.1017 / \mathrm{S} 0021859601001745$

Tamaki, M., H. Sato, H. Mitsuhashi and T. Kikawada, 2015. A study on "genomewide selection" for maize (Zea mays L.) breeding in Japanese public sectors: Heritability of maturity- and yield-related traits in the training population. JARQ, 49: 255-260. DOI: $10.6090 /$ jarq. 49.255

Yoshida, H. and M. Kamio, 1985. Differences in characteristics of earliness, partitioned by developmental stage between wheat and barley cultivars. Japanese J. Breed., 35: 323-331. DOI: $10.1270 /$ jsbbs1951.35.323

Zhang, T., X. Lin and G.F. Sassenrath, 2015. Current irrigation practices in the central United States reduce drought and extreme heat impacts for maize and soybean, but not for wheat. Sci. Total Environ., 508: 331-342. DOI: 10.1016/j.scitotenv.2014.12.004 